\title{
The split common fixed point problem for asymptotically nonexpansive semigroups in Banach spaces
}

Lin Wang ${ }^{1 *}$ and Zhaoli $\mathrm{Ma}^{2}$

\section{"Correspondence:}

WL64mail@aliyun.com

${ }^{1}$ College of Statistics and

Mathematics, Yunnan University of

Finance and Economics, Kunming,

Yunnan 650221, P.R. China

\begin{abstract}
In this paper, we propose an iteration method for finding a split common fixed point of asymptotically nonexpansive semigroups in the setting of two Banach spaces, and we obtain some weak and strong convergence theorems of the iteration scheme proposed. The results presented in the paper are new and improve and extend some recent corresponding results.
\end{abstract}

MSC: 47H09; 47J25

Keywords: split common fixed point problem; convergence; asymptotically nonexpansive semigroup; Banach space

\section{Introduction}

Let $E$ be a real normed linear space and $C$ be a nonempty closed convex subset of $E$. The mapping $T: C \rightarrow C$ is said to be nonexpansive if for all $x, y \in C$

$$
\|T x-T y\| \leq\|x-y\| .
$$

The mapping $T: C \rightarrow C$ is said to be asymptotically nonexpansive if there exists a sequence $\left\{k_{n}\right\} \subset[1, \infty)$ with $\lim _{n \rightarrow \infty} k_{n}=1$ such that for all $x, y \in C$ and each $n \geq 1$

$$
\left\|T^{n} x-T^{n} y\right\| \leq k_{n}\|x-y\|
$$

The class of nonexpansive mappings is one of the most important classes of mappings in nonlinear science. The class of asymptotically nonexpansive mappings is an important generalization of the class of nonexpansive mappings, which was introduced by Goebel and Kirk [1] in 1972. They proved that if $C$ is a nonempty closed convex subset of a real uniformly convex Banach space and $T$ is an asymptotically nonexpansive mapping, then $T$ has a fixed point.

Example 1.1 ([2]) Let $C$ be a unit ball in a real Hilbert space $l^{2}$ and let $S: C \rightarrow C$ be a mapping defined by

$$
S:\left(x_{1}, x_{2}, \ldots\right) \rightarrow\left(0, x_{1}^{2}, a_{2} x_{2}, a_{3} x_{3}, \ldots\right),
$$

(c) 2016 Wang and Ma. This article is distributed under the terms of the Creative Commons Attribution 4.0 International License (http://creativecommons.org/licenses/by/4.0/), which permits unrestricted use, distribution, and reproduction in any medium, provided you give appropriate credit to the original author(s) and the source, provide a link to the Creative Commons license, and indicate if changes were made. 
It is proved in Goebal and Kirk [1] that:

(i) $\|S x-S y\| \leq 2\|x-y\|$, for all $x, y \in C$;

(ii) $\left\|S^{n} x-S^{n} y\right\| \leq 2 \prod_{j=2}^{n} a_{j}\|x-y\|$, for all $x, y \in C, \forall n \geq 2$.

Taking $a_{j}=2^{-\frac{1}{2^{j-1}}}, j \geq 2$, it is easy to see that $\prod_{j=2}^{\infty} a_{j}=\frac{1}{2}$. So we can take $k_{1}=2$ and $k_{n}=2 \prod_{j=2}^{n} a_{j}, n \geq 2$, then

$$
\lim _{n \rightarrow \infty} k_{n}=\lim _{n \rightarrow \infty} 2 \prod_{j=2}^{n} 2^{-\frac{1}{2^{j-1}}}=1 .
$$

Therefore $S$ is an asymptotically nonexpansive mapping from $C$ into itself with $F(S)=$ $\{(0,0, \ldots, 0, \ldots)\}$.

Definition 1.2 ([3]) A one-parameter family $\mathcal{F}:=\{T(t): t \geq 0\}$ of $E$ into itself is called a strongly continuous semigroup of Lipschitzian mappings on $E$ if it satisfies the following conditions:

(i) $T(0) x=x$, for all $x \in E$;

(ii) $T(s+t)=T(s) T(t)$, for all $s, t \geq 0$;

(iii) for each $x \in E$, the mapping $t \mapsto T(t) x$ is continuous;

(iv) for each $t>0$, there exists a bounded measurable function $L(t):[0, \infty) \rightarrow[0, \infty)$ such that

$$
\|T(t) x-T(t) y\| \leq L(t)\|x-y\|, \quad \text { for all } x, y \in E .
$$

If the bounded measurable function $L(t)$ in (1.4) is such that $L(t) \geq 1$ for each $t>0$, $L(t)$ is nonincreasing in $t$, and $\lim _{t \rightarrow \infty} L(t)=1$, then the strong continuous semigroup of Lipschitzian mappings is said to be an asymptotically nonexpansive semigroup. We denote by $F(\mathcal{F})$ the set of all common fixed points of $\mathcal{F}$, that is,

$$
F(\mathcal{F}):=\{x \in E: T(t) x=x, 0 \leq t<\infty\}=\bigcap_{t \geq 0} F(T(t)) .
$$

If $\mathcal{F}$ satisfies (i)-(iii) and

$$
\limsup _{t \rightarrow \infty, x \in D}\|T(t) x-T(s) T(t) x\|=0, \quad \text { for all } s>0 \text { and bounded } D \subseteq C,
$$

then $\mathcal{F}$ is called uniformly asymptotically regular on $C$.

Example 1.3 ([4] (Example of asymptotically nonexpansive semigroup)) Let $E$ be an uniformly convex Banach space which admits a weakly continuous duality mapping. Let $L(E)$ be the space of all bounded linear operators on $E$. For $\Psi \in L(E)$, define $\mathcal{F}:=\left\{T(t): t \in R^{+}\right\}$ of bounded linear operators by using the following exponential expression:

$$
T(t)=e^{-t \Psi}:=\sum_{k=0}^{\infty} \frac{(-1)^{k}}{k !} t^{k} \Psi^{k} .
$$

Then the family $\mathcal{F}:=\left\{T(t): t \in R^{+}\right\}$satisfies the semigroup properties. Moreover, this family forms a one-parameter semigroup of self-mappings of $E$ because $e^{t \Psi}=\left[e^{-t \Psi}\right]^{-1}$ : $E \rightarrow E$ exists for each $t \in R^{+}$. 
In 1994, in finite dimensional Hilbert spaces, Censor and Elfving [5] introduced the split feasibility problem for modeling inverse problems which arise from phase retrievals and in medical imagine reconstruction [6]. It has been found that split feasibility problems can be used in various disciplines, such as imagine restoration, computer tomograph and radiation therapy treatment planning [7-9].

Let $H_{1}$ and $H_{2}$ be two real Hilbert spaces, $C$ and $Q$ be nonempty closed convex subsets of $H_{1}$ and $H_{2}$, respectively. The split feasibility problem is formulated as finding a point $q \in H_{1}$ such that

$$
q \in C \text { and } A q \in Q
$$

where $A: H_{1} \rightarrow H_{2}$ is a bounded linear operator.

If (1.7) has a solution, it is not hard to see that $x \in C$ solves (1.7) if and only if it solves the following fixed point equation:

$$
x=P_{C}\left(I-\gamma A^{*}\left(I-P_{Q}\right) A\right) x, \quad x \in C,
$$

where $P_{C}$ and $P_{Q}$ are the projections onto $C$ and $Q$, respectively, $\gamma$ is a positive constant, and $A^{*}$ denotes the adjoint of $A$.

When $C$ and $Q$ in (1.7) are the sets of fixed points of two nonlinear mappings, and $C$ and $Q$ are nonempty closed convex subsets of $H_{1}$ and $H_{2}$, respectively, then the split feasibility problem (1.7) is also said to be split common fixed point problem [10]. It is well known that each nonempty closed convex subset of a Hilbert space is the set of fixed points of its projection, therefore, the split common fixed point problem may be considered as a generalization of split feasibility problem.

In the setting of two Hilbert spaces, for demicontractive mappings, Moudafi [10] proposed an iteration scheme and obtained a weak convergence theorem of the split common fixed point problem. Since then, the split common fixed point problems of other nonlinear mappings in the setting of two Hilbert spaces have been studied by some authors; see, for instance, [2, 11-14]. Especially, Cholamjiak et al. [15] obtained a strong convergence theorem of split common fixed point problem involving a uniformly asymptotically regular nonexpansive semigroup and a total asymptotically strict pseudo-contractive mapping in Hilbert spaces.

In 2015, in the setting of one Hilbert space and one Banach space, Takahashi [16] investigated the split feasibility problem and split common null point problem, and obtained some strong and weak convergence theorems under some mild control conditions.

Recently, in the setting of two Banach spaces, Tang et al. [17] obtained a weak convergence theorem and a strong convergence theorem of the split common fixed point problem involving a quasi-strict pseudo-contractive mapping and an asymptotically nonexpansive mapping under the following assumptions:

(1) $E_{1}$ is a real uniformly convex and 2-uniformly smooth Banach space having the Opial property and the best smoothness constant $k$ satisfying $0<k<\frac{1}{\sqrt{2}}$.

(2) $E_{2}$ is a real Banach space.

(3) $A: E_{1} \rightarrow E_{2}$ be a bounded linear operator and $A^{*}$ is the adjoint of $A$.

(4) $S: E_{1} \rightarrow E_{1}$ is an $\left\{l_{n}\right\}$-asymptotically nonexpansive mapping with $\left\{l_{n}\right\} \subset(1, \infty)$ and $l_{n} \rightarrow 1 . T: E_{2} \rightarrow E_{2}$ is a $\tau$-quasi-strict pseudo-contractive mapping with $F(S) \neq \emptyset$ and $F(T) \neq \emptyset$, and $T$ is demiclosed at zero. 
Theorem 1.4 ([17]) Let $E_{1}, E_{2}, A, S, T$, and $\left\{l_{n}\right\}$ be the same as above. For each $x_{1} \in E_{1}$, let $\left\{x_{n}\right\}$ be the sequence generated by

$$
\left\{\begin{array}{l}
z_{n}=x_{n}+\gamma J_{1}^{-1} A^{*} J_{2}(T-I) A x_{n}, \\
x_{n+1}=\left(1-\alpha_{n}\right) z_{n}+\alpha_{n} S^{n}\left(z_{n}\right), \quad \forall n \geq 1
\end{array}\right.
$$

where $\left\{\alpha_{n}\right\}$ is a sequence in $(0,1)$ with $\liminf _{n \rightarrow \infty} \alpha_{n}\left(1-\alpha_{n}\right)>0, \gamma$ is a positive constant satisfying $0<\gamma<\min \left\{\frac{1-2 k^{2}}{\|A\|^{2}}, \frac{1-\tau}{\|A\|^{2}}\right\},\left\{l_{n}\right\}$ is a sequence in $[0, \infty)$ with $L=\sup _{n \geq 1}\left\{l_{n}\right\}$ and $\sum_{n=1}^{\infty}\left(l_{n}-1\right)<\infty$.

(I) If $\Gamma=\{p \in F(S): A p \in F(T)\} \neq \phi$, then the sequence $\left\{x_{n}\right\}$ converges weakly to a point $x^{*} \in \Gamma$.

(II) In addition, if $\Gamma=\{p \in F(S): A p \in F(T)\} \neq \phi$ and $S$ is semi-compact, then $\left\{x_{n}\right\}$ converges strongly to a point $x^{*} \in \Gamma$.

This naturally brings about the following question:

Question Can we obtain the convergence results of split common fixed point problem for asymptotically nonexpansive semigroups in the setting of two Banach spaces?

In this paper, motivated and inspired by the recent research going on in the direction of split feasibility problems and split common fixed point problems, we construct an iteration scheme to approximate a split common fixed point of two asymptotically nonexpansive semigroups in the setting of two Banach spaces. Under some suitable conditions on parameters, the iteration scheme proposed is shown to converge strongly and weakly to a split common fixed point of asymptotically nonexpansive semigroups in two Banach spaces.

\section{Preliminaries}

We now recall some definitions and elementary facts which will be used in the proofs of our main results.

Let $E$ be a real Banach space with the dual $E^{*}$. The normalized duality mapping $J$ from $E$ to $2^{E^{*}}$ is defined by

$$
J x=\left\{x^{*} \in E^{*}:\left\langle x, x^{*}\right\rangle=\|x\|^{2}=\left\|x^{*}\right\|^{2}\right\}, \quad \forall x \in E,
$$

where $\langle\cdot, \cdot\rangle$ denotes the generalized duality pairing between $E$ and $E^{*}$.

A Banach space $E$ is said to be strictly convex if $\frac{\|x+y\|}{2} \leq 1$ for all $x, y \in U=\{z \in E:\|z\|=1\}$ with $x \neq y$. The modulus of convexity of $E$ is defined by

$$
\delta_{E}(\epsilon)=\inf \left\{1-\left\|\frac{1}{2}(x+y)\right\|:\|x\|,\|y\| \leq 1,\|x-y\| \geq \epsilon\right\}
$$

for all $\epsilon \in[0,2]$. $E$ is said to be uniformly convex if $\delta_{E}(0)=0$, and $\delta_{E}(\epsilon)>0$ for all $0<\epsilon \leq 2$. A Hilbert space is 2-uniformly convex, while $L^{p}$ is $\max \{p, 2\}$-uniformly convex for every $p>1$.

Let $\rho_{E}:[0, \infty) \rightarrow[0, \infty)$ be the modulus of smoothness of $E$ defined by

$$
\rho_{E}(t)=\sup \left\{\frac{1}{2}(\|x+y\|+\|x-y\|)-1: x \in U,\|y\| \leq t\right\} .
$$


A Banach space $E$ is said to be uniformly smooth if $\frac{\rho_{E}(t)}{t} \rightarrow 0$ as $t \rightarrow 0$. A typical example of uniformly smooth Banach space is $L^{p}$, where $p>1$. More precisely, $L^{p}$ is $\min \{p, 2\}$ uniformly smooth for every $p>1$. Let $q$ be a fixed real number with $q>1$, then a Banach space $E$ is said to be $q$-uniformly smooth if there exists a constant $c>0$ such that $\rho_{E}(t) \leq c t^{q}$ for all $t>0$. It is well known that every $q$-uniformly smooth Banach space is uniformly smooth.

Lemma 2.1 ([18]) Given a number $r>0$. A real Banach space $E$ is uniformly convex if and only if there exists a continuous strictly increasing function $g:[0, \infty) \rightarrow[0, \infty)$ with $g(0)=0$ such that

$$
\|t x+(1-t) y\|^{2} \leq t\|x\|^{2}+(1-t)\|y\|^{2}-t(1-t) g(\|x-y\|)
$$

for all $x, y \in E, t \in[0,1]$, with $\|x\| \leq r$ and $\|y\| \leq r$.

Let $E_{1}$ and $E_{2}$ be two real Banach spaces, $C$ and $Q$ be nonempty closed convex subsets of $E_{1}$ and $E_{2}$, respectively. $A: E_{1} \rightarrow E_{2}$ is a bounded linear operator such that $A \neq 0$. Then the split common fixed point problem is to find a point $q \in E_{1}$ with the property:

$$
q \in F(S) \quad \text { and } \quad A q \in F(T), \quad \text { i.e., } q \in F(S) \cap A^{-1} F(T),
$$

where $F(S)$ and $F(T)$ denote the sets of fixed points of $S$ and $T$, respectively.

Let $T: C \rightarrow C$ be a mapping with $F(T) \neq \emptyset$. Then $T$ is said to be demiclosed at zero if for any $\left\{x_{n}\right\} \subset C$ with $x_{n} \rightarrow x$ and $\left\|x_{n}-T x_{n}\right\| \rightarrow 0, x=T x$.

A mapping $T: C \rightarrow C$ is said to be semi-compact, if for any sequence $\left\{x_{n}\right\}$ in $C$ such that $\left\|x_{n}-T x_{n}\right\| \rightarrow 0(n \rightarrow \infty)$, there exists a subsequence $\left\{x_{n_{j}}\right\}$ of $\left\{x_{n}\right\}$ such that $\left\{x_{x_{j}}\right\}$ converges strongly to $x^{*} \in C$.

A Banach space $E$ is said to satisfy Opial property if for any sequence $\left\{x_{n}\right\}$ in $E, x_{n} \rightarrow x$, for any $y \in E$ with $y \neq x$, we have

$$
\liminf _{n \rightarrow \infty}\left\|x_{n}-x\right\|<\liminf _{n \rightarrow \infty}\left\|x_{n}-y\right\|
$$

Lemma 2.2 ([19]) Let E be a real uniformly convex Banach space, $C$ be a nonempty closed subset of $E$, and let $T: C \rightarrow C$ be an asymptotically nonexpansive mapping. Then $I-T$ is demiclosed at zero, that is, if $\left\{x_{n}\right\} \subset C$ converges weakly to a point $p \in C$ and $\lim _{n \rightarrow \infty} \| x_{n}-$ $T x_{n} \|=0$, then $p=T p$.

Lemma 2.3 ([20]) Let $\left\{a_{n}\right\}$ and $\left\{\alpha_{n}\right\}$ be two nonnegative real number sequences and satisfy

$$
a_{n+1} \leq\left(1+\alpha_{n}\right) a_{n}, \quad \forall n \geq 1,
$$

where $a_{n} \geq 0, \alpha_{n} \geq 0$ and $\sum_{n=1}^{\infty} \alpha_{n}<\infty$. Then

(1) $\lim _{n \rightarrow \infty} a_{n}$ exists;

(2) if $\liminf _{n \rightarrow \infty} a_{n}=0$, then $\lim _{n \rightarrow \infty} a_{n}=0$. 
Lemma 2.4 ([18]) Let E be a 2-uniformly smooth Banach space with the best smoothness constants $K>0$. Then the following inequality holds:

$$
\|x+y\|^{2} \leq\|x\|^{2}+2\langle y, J x\rangle+2\|K y\|^{2}, \quad \forall x, y \in E
$$

\section{Main results}

Theorem 3.1 Let $E_{1}$ be a real uniformly convex and 2-uniformly smooth Banach space satisfying Opial's condition and with the best smoothness constant $k$ satisfying $0<k<\frac{1}{\sqrt{2}}$, $E_{2}$ be a real Banach space, and $A: E_{1} \rightarrow E_{2}$ be a bounded linear operator and $A^{*}$ be the adjoint of $A$. Let $\{S(t): t \geq 0\}: E_{1} \rightarrow E_{1}$ be a uniformly asymptotically regular asymptotically nonexpansive semigroup with a bounded measurable function $L^{(1)}(t):[0, \infty) \rightarrow[1, \infty)$ satisfying $\lim _{t \rightarrow \infty} L^{(1)}(t)=1$ and $C:=\bigcap_{t \geq 0} F(S(t)) \neq \emptyset,\{T(t): t \geq 0\}: E_{2} \rightarrow E_{2}$ be a uniformly asymptotically regular family of asymptotically nonexpansive semigroup with a bounded measurable function $L^{(2)}(t):[0, \infty) \rightarrow[1, \infty)$ satisfying $\lim _{t \rightarrow \infty} L^{(2)}(t)=1$ and $Q:=\bigcap_{t \geq 0} F(T(t)) \neq \emptyset$, respectively. Let $\left\{x_{n}\right\}$ be a sequence generated by $x_{1} \in E_{1}$,

$$
\left\{\begin{array}{l}
z_{n}=x_{n}+\gamma J_{1}^{-1} A^{*} J_{2}\left(T\left(t_{n}\right)-I\right) A x_{n}, \quad \forall n \geq 1, \\
x_{n+1}=\left(1-\alpha_{n}\right) z_{n}+\alpha_{n} S\left(t_{n}\right)\left(z_{n}\right),
\end{array}\right.
$$

where $\left\{t_{n}\right\}$ is a sequence of real numbers, $\left\{\alpha_{n}\right\}$ is a sequence in $(0,1)$, and $\gamma$ is a positive constant satisfying

(1) $t_{n}>0$ and $\lim _{n \rightarrow \infty} t_{n}=\infty$;

(2) $L(t)=\max \left\{L^{(1)}(t), L^{(2)}(t)\right\}$ and $\sum_{n=1}^{\infty}\left(L^{2}\left(t_{n}\right)-1\right)<\infty$;

(3) $M=\sup _{n} L^{2}\left(t_{n}\right), \liminf _{n \rightarrow \infty} \alpha_{n}\left(1-\alpha_{n}\right)>0$ and $0<\gamma<\min \left\{\frac{1-2 k^{2}}{\|A\|^{2} M}, \frac{1}{\|A\|^{2}}\right\}$.

(I) If $\Gamma=\{p \in C: A p \in Q\} \neq \emptyset$, then the sequence $\left\{x_{n}\right\}$ converges weakly to a split common fixed point $x^{*} \in \Gamma$.

(II) In addition, if $\Gamma=\{p \in C: A p \in Q\} \neq \emptyset$ and there exists at least one $S(t) \in\{S(t): t \geq 0\}$ that is semi-compact, then $\left\{x_{n}\right\}$ converges strongly to a split common fixed point $x^{*} \in \Gamma$.

Proof Now we prove the conclusion (I).

We shall divide the proof into four steps.

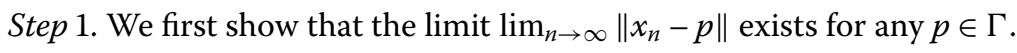

For any given $p \in \Gamma$, then $p \in C$ and $A p \in Q$. It follows from (1.4), (3.1), and Lemma 2.4 that

$$
\begin{aligned}
\left\|z_{n}-p\right\|^{2}= & \left\|\left(x_{n}-p\right)+\gamma J_{1}^{-1} A^{*} J_{2}\left(T\left(t_{n}\right)-I\right) A x_{n}\right\|^{2} \\
\leq & \left\|\gamma J_{1}^{-1} A^{*} J_{2}\left(T\left(t_{n}\right)-I\right) A x_{n}\right\|^{2}+2 \gamma\left\langle x_{n}-p, A^{*} J_{2}\left(T\left(t_{n}\right)-I\right) A x_{n}\right\rangle \\
& +2 k^{2}\left\|x_{n}-p\right\|^{2} \\
\leq & \gamma^{2}\|A\|^{2}\left\|\left(T\left(t_{n}\right)-I\right) A x_{n}\right\|^{2}+2 \gamma\left\langle A x_{n}-A p, J_{2}\left(T\left(t_{n}\right)-I\right) A x_{n}\right\rangle \\
& +2 k^{2}\left\|x_{n}-p\right\|^{2} \\
= & \gamma^{2}\|A\|^{2}\left\|\left(T\left(t_{n}\right)-I\right) A x_{n}\right\|^{2}+2 k^{2}\left\|x_{n}-p\right\|^{2} \\
& +2 \gamma\left\langle A x_{n}-T\left(t_{n}\right) A x_{n}+T\left(t_{n}\right) A x_{n}-T\left(t_{n}\right) A p, J_{2}\left(T\left(t_{n}\right)-I\right) A x_{n}\right\rangle
\end{aligned}
$$




$$
\begin{aligned}
= & \gamma^{2}\|A\|^{2}\left\|\left(T\left(t_{n}\right)-I\right) A x_{n}\right\|^{2}-2 \gamma\left\|A x_{n}-T\left(t_{n}\right) A x_{n}\right\|^{2} \\
& +2 \gamma\left\langle T\left(t_{n}\right) A x_{n}-T\left(t_{n}\right) A p, J_{2}\left(T\left(t_{n}\right)-I\right) A x_{n}\right\rangle+2 k^{2}\left\|x_{n}-p\right\|^{2} \\
\leq & \gamma^{2}\|A\|^{2}\left\|\left(T\left(t_{n}\right)-I\right) A x_{n}\right\|^{2}-2 \gamma\left\|\left(T\left(t_{n}\right)-I\right) A x_{n}\right\|^{2} \\
& +\gamma\left[\left\|T\left(t_{n}\right) A x_{n}-T\left(t_{n}\right) A p\right\|^{2}+\left\|\left(T\left(t_{n}\right)-I\right) A x_{n}\right\|^{2}\right]+2 k^{2}\left\|x_{n}-p\right\|^{2} \\
\leq & \gamma\left(\gamma\|A\|^{2}-1\right)\left\|\left(T\left(t_{n}\right)-I\right) A x_{n}\right\|^{2}+\gamma\|A\|^{2} L^{2}\left(t_{n}\right)\left\|x_{n}-p\right\|^{2}+2 k^{2}\left\|x_{n}-p\right\|^{2} \\
= & \left(\gamma\|A\|^{2} L^{2}\left(t_{n}\right)+2 k^{2}\right)\left\|x_{n}-p\right\|^{2}-\gamma\left(1-\gamma\|A\|^{2}\right)\left\|\left(T\left(t_{n}\right)-I\right) A x_{n}\right\|^{2} .
\end{aligned}
$$

It follows from (3.1), (3.2), and Lemma 2.1 that

$$
\begin{aligned}
\left\|x_{n+1}-p\right\|^{2}= & \left\|z_{n}-p+\alpha_{n}\left(S\left(t_{n}\right) z_{n}-z_{n}\right)\right\|^{2} \\
\leq & \left(1-\alpha_{n}\right)\left\|z_{n}-p\right\|^{2}+\alpha_{n}\left\|S\left(t_{n}\right) z_{n}-p\right\|^{2}-\alpha_{n}\left(1-\alpha_{n}\right) g\left(\left\|z_{n}-S\left(t_{n}\right) z_{n}\right\|\right) \\
\leq & \left(1-\alpha_{n}\right)\left\|z_{n}-p\right\|^{2}+\alpha_{n} L^{2}\left(t_{n}\right)\left\|z_{n}-p\right\|^{2}-\alpha_{n}\left(1-\alpha_{n}\right) g\left(\left\|z_{n}-S\left(t_{n}\right) z_{n}\right\|\right) \\
= & \left(1+\alpha_{n}\left(L^{2}\left(t_{n}\right)-1\right)\right)\left\|z_{n}-p\right\|^{2}-\alpha_{n}\left(1-\alpha_{n}\right) g\left(\left\|z_{n}-S\left({ }^{n} t_{n}\right) z_{n}\right\|\right) \\
\leq & \left(1+\alpha_{n}\left(L^{2}\left(t_{n}\right)-1\right)\right)\left[\left(\gamma\|A\|^{2} L^{2}\left(t_{n}\right)+2 k^{2}\right)\left\|x_{n}-p\right\|^{2}\right. \\
& \left.-\gamma\left(1-\gamma\|A\|^{2}\right)\left\|\left(T\left(t_{n}\right)-I\right) A x_{n}\right\|^{2}\right]-\alpha_{n}\left(1-\alpha_{n}\right) g\left(\left\|z_{n}-S\left(t_{n}\right) z_{n}\right\| 4\right) \\
\leq & \left(1+\alpha_{n}\left(L^{2}\left(t_{n}\right)-1\right)\right)\left(\gamma\|A\|^{2} M+2 k^{2}\right)\left\|x_{n}-p\right\|^{2} \\
& -\left(1+\alpha_{n}\left(L^{2}\left(t_{n}\right)-1\right)\right) \gamma\left(1-\gamma\|A\|^{2}\right)\left\|\left(T\left(t_{n}\right)-I\right) A x_{n}\right\|^{2} \\
& -\alpha_{n}\left(1-\alpha_{n}\right) g\left(\left\|z_{n}-S\left(t_{n}\right) z_{n}\right\|\right) .
\end{aligned}
$$

Since $\lim _{t_{n} \rightarrow \infty} L\left(t_{n}\right)=1, \sum_{n=1}^{\infty}\left(L^{2}\left(t_{n}\right)-1\right)<\infty, 0<k<\frac{1}{\sqrt{2}}, 0<\gamma<\frac{1-2 k^{2}}{\|A\|^{2} M}$, so $0<$ $\gamma\|A\|^{2} M+2 k^{2}<1$, and from (3.3) and Lemma 2.3 we see that the $\lim _{n \rightarrow \infty}\left\|x_{n}-p\right\|$ exists. This implies that $\left\{x_{n}\right\}$ is bounded. Further, it follows from (3.2) that $\left\{z_{n}\right\}$ is bounded, too.

Step 2. We prove that $\lim _{n \rightarrow \infty}\left\|x_{n+1}-x_{n}\right\|=0$ and $\lim _{n \rightarrow \infty}\left\|z_{n+1}-z_{n}\right\|=0$.

It follows from (3.3) that

$$
\begin{aligned}
\left\|x_{n+1}-p\right\|^{2} \leq & \left(1+\alpha_{n}\left(L^{2}\left(t_{n}\right)-1\right)\right)\left(\gamma\|A\|^{2} M+2 k^{2}\right)\left\|x_{n}-p\right\|^{2} \\
& -\gamma\left(1-\gamma\|A\|^{2}\right)\left\|\left(T\left(t_{n}\right)-I\right) A x_{n}\right\|^{2}-\alpha_{n}\left(1-\alpha_{n}\right) g\left(\left\|z_{n}-S\left(t_{n}\right) z_{n}\right\|\right) .
\end{aligned}
$$

From (3.4), we have

$$
\begin{aligned}
& \gamma\left(1-\gamma\|A\|^{2}\right)\left\|\left(T\left(t_{n}\right)-I\right) A x_{n}\right\|^{2}+\alpha_{n}\left(1-\alpha_{n}\right) g\left(\left\|z_{n}-S\left(t_{n}\right) z_{n}\right\|\right) \\
& \quad \leq\left(1+\alpha_{n}\left(L^{2}\left(t_{n}\right)-1\right)\right)\left(\gamma\|A\|^{2} L^{2}\left(t_{n}\right)+2 k^{2}\right)\left\|x_{n}-p\right\|^{2}-\left\|x_{n+1}-p\right\|^{2} \\
& \quad=\left\|x_{n}-p\right\|^{2}+\alpha_{n}\left(L^{2}\left(t_{n}\right)-1\right)\left(\gamma\|A\|^{2} L^{2}\left(t_{n}\right)+2 k^{2}\right)\left\|x_{n}-p\right\|^{2}-\left\|x_{n+1}-p\right\|^{2} .
\end{aligned}
$$

This implies that

$$
\lim _{n \rightarrow \infty}\left\|\left(T\left(t_{n}\right)-I\right) A x_{n}\right\|=0
$$


and

$$
\lim _{n \rightarrow \infty} g\left(\left\|z_{n}-S\left(t_{n}\right) z_{n}\right\|\right)=0
$$

By virtue of Lemma 2.1 and the property of $g$, we may get

$$
\lim _{n \rightarrow \infty}\left\|z_{n}-S\left(t_{n}\right) z_{n}\right\|=0
$$

It follows from (3.1) that

$$
\begin{aligned}
\left\|x_{n+1}-x_{n}\right\|= & \left\|\left(1-\alpha_{n}\right) z_{n}+\alpha_{n} S\left(t_{n}\right) z_{n}-x_{n}\right\| \\
= & \left\|\left(1-\alpha_{n}\right)\left[x_{n}+\gamma J_{1}^{-1} A^{*} J_{2}\left(T\left(t_{n}\right)-I\right) A x_{n}\right]+\alpha_{n} S\left(t_{n}\right) z_{n}-x_{n}\right\| \\
= & \left\|\left(1-\alpha_{n}\right) \gamma J_{1}^{-1} A^{*} J_{2}\left(T\left(t_{n}\right)-I\right) A x_{n}+\alpha_{n}\left(S\left(t_{n}\right) z_{n}-x_{n}\right)\right\| \\
= & \left\|\left(1-\alpha_{n}\right) \gamma J_{1}^{-1} A^{*} J_{2}\left(T\left(t_{n}\right)-I\right) A x_{n}+\alpha_{n}\left(S\left(t_{n}\right) z_{n}-z_{n}\right)+\alpha_{n}\left(z_{n}-x_{n}\right)\right\| \\
= & \|\left(1-\alpha_{n}\right) \gamma J_{1}^{-1} A^{*} J_{2}\left(T\left(t_{n}\right)-I\right) A x_{n}+\alpha_{n}\left(S\left(t_{n}\right) z_{n}-z_{n}\right) \\
& +\alpha_{n} \gamma J_{1}^{-1} A^{*} J_{2}\left(T\left(t_{n}\right)-I\right) A x_{n} \| \\
= & \left\|\gamma J_{1}^{-1} A^{*} J_{2}\left(T\left(t_{n}\right)-I\right) A x_{n}+\alpha_{n}\left(S\left(t_{n}\right) z_{n}-z_{n}\right)\right\| \\
\leq & \left\|\gamma J_{1}^{-1} A^{*} J_{2}\left(T\left(t_{n}\right)-I\right) A x_{n}\right\|+\alpha_{n}\left\|S\left(t_{n}\right) z_{n}-z_{n}\right\| .
\end{aligned}
$$

It follows from (3.6), (3.8), and (3.9) that

$$
\lim _{n \rightarrow \infty}\left\|x_{n+1}-x_{n}\right\|=0 .
$$

In addition, since

$$
\begin{aligned}
\left\|\left(T\left(t_{n}\right)-I\right) A x_{n+1}\right\| & =\left\|\left(T\left(t_{n}\right)-I\right) A x_{n+1}-\left(T\left(t_{n}\right)-I\right) A x_{n}+\left(T\left(t_{n}\right)-I\right) A x_{n}\right\| \\
& \leq\left(L\left(t_{n}\right)+1\right)\|A\|\left\|x_{n+1}-x_{n}\right\|+\left\|\left(T\left(t_{n}\right)-I\right) A x_{n}\right\|,
\end{aligned}
$$

it follows from (3.6) and (3.10) that

$$
\lim _{n \rightarrow \infty}\left\|\left(T\left(t_{n}\right)-I\right) A x_{n+1}\right\|=0 .
$$

Similarly,

$$
\begin{aligned}
& \left\|z_{n+1}-z_{n}\right\| \\
& \quad=\left\|x_{n+1}+\gamma J_{1}^{-1} A^{*} J_{2}\left(T\left(t_{n}\right)-I\right) A x_{n+1}-x_{n}-\gamma J_{1}^{-1} A^{*} J_{2}\left(T\left(t_{n}\right)-I\right) A x_{n}\right\| \\
& \quad \leq\left\|\left(x_{n+1}-x_{n}\right)+\gamma J_{1}^{-1} A^{*} J_{2}\left(T\left(t_{n}\right)-I\right) A x_{n+1}-\gamma J_{1}^{-1} A^{*} J_{2}\left(T\left(t_{n}\right)-I\right) A x_{n}\right\| \\
& \quad \leq\left\|x_{n+1}-x_{n}\right\|+\left\|\gamma J_{1}^{-1} A^{*} J_{2}\left(T\left(t_{n}\right)-I\right) A x_{n+1}\right\|+\left\|\gamma J_{1}^{-1} A^{*} J_{2}\left(T\left(t_{n}\right)-I\right) A x_{n}\right\| .
\end{aligned}
$$

In view of (3.6), (3.10), (3.11), and (3.12), we have

$$
\lim _{n \rightarrow \infty}\left\|z_{n+1}-z_{n}\right\|=0
$$


In addition,

$$
\left\|x_{n}-z_{n}\right\|=\left\|J_{1}\left(x_{n}-z_{n}\right)\right\|=\left\|\gamma A^{*} J_{2}\left(T\left(t_{n}\right)-I\right) A x_{n}\right\| \leq \gamma\|A\|\left\|\left(T\left(t_{n}\right)-I\right) A x_{n}\right\|,
$$

from (3.6), we have

$$
\lim _{n \rightarrow \infty}\left\|x_{n}-z_{n}\right\|=0
$$

Step 3. We prove that $\lim _{n \rightarrow \infty}\left\|z_{n}-S(t) z_{n}\right\|=0$ and $\lim _{n \rightarrow \infty}\left\|(T(t)-I) A z_{n}\right\|=0$ for all $t \geq 0$.

Since $\{S(t): t \geq 0\}$ and $\{T(t): t \geq 0\}$ are uniformly asymptotically regular, and $\lim _{n \rightarrow \infty} t_{n}=\infty$, for all $t \geq 0$,

$$
\lim _{n \rightarrow \infty}\left\|S(t) S\left(t_{n}\right) z_{n}-S\left(t_{n}\right) z_{n}\right\| \leq \limsup _{n \rightarrow \infty, x \in C}\left\|S(t) S\left(t_{n}\right) x-S\left(t_{n}\right) x\right\|=0
$$

and

$$
\begin{aligned}
& \lim _{n \rightarrow \infty}\left\|T(t)\left(T\left(t_{n}\right)-I\right) A z_{n}-(T(t)-I) A z_{n}\right\| \\
& \quad \leq \limsup _{n \rightarrow \infty, x \in C}\left\|T(t)\left(T\left(t_{n}\right)-I\right) A x-(T(t)-I) A x\right\|=0 .
\end{aligned}
$$

Since $\{S(t) x\}$ is continuous on $t$ for all $x \in E_{1}$, and

$$
\begin{aligned}
\left\|z_{n}-S(t) z_{n}\right\| \leq & \left\|z_{n}-S\left(t_{n}\right) z_{n}\right\|+\left\|S\left(t_{n}\right) z_{n}-S(t) S\left(t_{n}\right) z_{n}\right\| \\
& +\left\|S(t) S\left(t_{n}\right) z_{n}-S(t) z_{n}\right\|,
\end{aligned}
$$

it follows from (3.6) and (3.16) that

$$
\lim _{n \rightarrow \infty}\left\|z_{n}-S(t) z_{n}\right\|=0
$$

Similarly,

$$
\lim _{n \rightarrow \infty}\left\|(T(t)-I) A x_{n}\right\|=0 .
$$

Step 4 . We prove that $\left\{x_{n}\right\}$ converges weakly to a point $x^{*} \in \Gamma$.

By the reflexivity of Banach space $E_{1}$ and boundedness of $\left\{x_{n}\right\}$, there exists a subsequence $\left\{x_{n_{i}}\right\}$ of $\left\{x_{n}\right\}$ converging weakly to $x^{*}$. By using (3.15) this implies that $\left\{z_{n_{i}}\right\}$ of $\left\{z_{n}\right\}$ converges weakly to $x^{*}$, too. Since $S(t)$ is asymptotically nonexpansive for all $t \geq 0$, it is demiclosed at zero, we know from Lemma 2.2 that $x^{*} \in F(S(t))$.

On the other hand, since $A$ is a bounded linear operator, we know that $\left\{A x_{n_{i}}\right\}$ converges weakly to $A x^{*}$. It follows from (3.20) that $\lim _{n_{i} \rightarrow \infty}\left\|(T(t)-I) A x_{n_{i}}\right\|=0$. Since $T(t)$ is demiclosed at zero for all $t \geq 0$, we have $A x^{*} \in F(T(t))$. This means that $x^{*} \in \Gamma$.

We now prove that $\left\{x_{n}\right\}$ converges weakly to $x^{*} \in \Gamma$. 
In fact, if there exists another subsequence $\left\{x_{n_{j}}\right\}$ of $\left\{x_{n}\right\}$ such that $\left\{x_{n_{j}}\right\}$ converges weakly to $y^{*} \in E_{1}$, we also know that $y^{*} \in F(T(t))$. By the assumption that $E_{1}$ satisfies Opial's condition, we have

$$
\begin{aligned}
\liminf _{n_{i} \rightarrow \infty}\left\|x_{n_{i}}-x^{*}\right\| & <\liminf _{n_{i} \rightarrow \infty}\left\|x_{n_{i}}-y^{*}\right\| \\
& =\liminf _{n \rightarrow \infty}\left\|x_{n}-y^{*}\right\| \\
& =\liminf _{n_{j} \rightarrow \infty}\left\|x_{n_{j}}-y^{*}\right\| \\
& <\liminf _{n_{i} \rightarrow \infty}\left\|x_{n_{i}}-x^{*}\right\| \\
& =\liminf _{n \rightarrow \infty}\left\|x_{n}-x^{*}\right\|=\liminf _{n_{i} \rightarrow \infty}\left\|x_{n_{i}}-x^{*}\right\| .
\end{aligned}
$$

This is a contradiction. Therefore $\left\{x_{n}\right\}$ converges weakly to $x^{*} \in \Gamma$. The proof of conclusion (I) is completed.

Next, we prove conclusion (II).

Since there exists at least one $S(t) \in\{S(t): t \geq 0\}$ that is semi-compact and $\lim _{n \rightarrow \infty} \| z_{n}$ $S(t) z_{n} \|=0$ for all $t \geq 0$, there exists subsequence $\left\{z_{n_{j}}\right\}$ of $\left\{z_{n}\right\}$ such that $\left\{z_{n_{j}}\right\}$ converges strongly to $\mu^{*} \in E_{1}$. By using (3.15) again, we know that the subsequence $\left\{x_{n_{j}}\right\}$ of $\left\{x_{n}\right\}$ converges strongly to $\mu^{*}$. Due to $\left\{x_{n}\right\}$ converging weakly to $x^{*}$, we obtain $\mu^{*}=x^{*}$. Since $\lim _{n \rightarrow \infty}\left\|x_{n}-x^{*}\right\|$ exists and $\lim _{n \rightarrow \infty}\left\|x_{n_{j}}-x^{*}\right\|=0$, we know that $\left\{x_{n}\right\}$ converges strongly to $x^{*} \in \Gamma$. This completes the proof of conclusion (II).

Corollary 3.2 Let $E_{1}$ be a real uniformly convex and 2-uniformly smooth Banach space satisfying Opial's condition and with the best smoothness constant $k$ satisfying $0<k<\frac{1}{\sqrt{2}}$, $E_{2}$ be a real Banach space, and $A: E_{1} \rightarrow E_{2}$ be a bounded linear operator and $A^{*}$ is the adjoint of $A,\{S(t): t \geq 0\}: E_{1} \rightarrow E_{1}$ and $\{T(t): t \geq 0\}: E_{2} \rightarrow E_{2}$ be two-parameter nonexpansive semigroups satisfying $C:=\bigcap_{t \geq 0} F(S(t)) \neq \emptyset$ and $Q:=\bigcap_{t \geq 0} F(T(t)) \neq \emptyset$, respectively. Let $\left\{x_{n}\right\}$ be a sequence generated by $x_{1} \in E_{1}$,

$$
\left\{\begin{array}{l}
z_{n}=x_{n}+\gamma J_{1}^{-1} A^{*} J_{2}\left(T\left(t_{n}\right)-I\right) A x_{n}, \quad \forall n \geq 1, \\
x_{n+1}=\left(1-\alpha_{n}\right) z_{n}+\alpha_{n} S\left(t_{n}\right)\left(z_{n}\right),
\end{array}\right.
$$

where $\left\{t_{n}\right\}$ is a sequence of real numbers satisfying $t_{n}>0$ and $\lim _{n \rightarrow \infty} t_{n}=\infty,\left\{\alpha_{n}\right\}$ is a sequence in $(0,1)$ satisfying $\liminf _{n \rightarrow \infty} \alpha_{n}\left(1-\alpha_{n}\right)>0, \gamma$ is a positive constant satisfying $0<\gamma<\frac{1-2 k^{2}}{\|A\|^{2}}$.

(I) If $\Gamma=\{p \in C: A p \in Q\} \neq \emptyset$, then the sequence $\left\{x_{n}\right\}$ converges weakly to a split common fixed point $x^{*} \in \Gamma$.

(II) In addition, if $\Gamma=\{p \in C: A p \in Q\} \neq \emptyset$ and there exists at least one $S(t) \in\{S(t): t \geq 0\}$ that is semi-compact, then $\left\{x_{n}\right\}$ converges strongly to a split common fixed point $x^{*} \in \Gamma$.

\section{Application to hierarchical variational inequality problem in Banach spaces}

Let $E$ be a strictly convex and real reflexive Banach space and $K$ be a nonempty closed and convex subset of $E$. Then, for any $x \in E$, there exists a unique element $z \in K$ such that $\|x-z\| \leq\|x-y\|$ for all $y \in K$. Putting $z=P_{K} x$, we call $P_{K}$ the metric projection of $E$ onto $K$. 
Lemma 4.1 ([21]) Let E be a smooth, strictly convex, and reflexive Banach space, and $K$ be a nonempty, closed, and convex subset of $E$. Let $x \in E$ and $z \in K$. Then the following conditions are equivalent:

(i) $z=P_{K} x$;

(ii) $\langle z-y, J(x-z)\rangle \geq 0, \forall y \in K$, where $J$ is the normalized duality mapping on $E$.

Definition 4.2 ([17]) Let $E$ be a smooth, strictly convex, and reflexive Banach space, and $K$ be a nonempty, closed and convex subset of $E$. Let $S: K \rightarrow K$ be a nonlinear mapping with $F(S)$ being a nonempty, closed, and convex subset of $K$ and $V: K \rightarrow K$ be a nonlinear mapping. The so-called hierarchical variational inequality problem for a mapping $S$ with respect to a mapping $V$ in Banach spaces is to find $x \in F(S)$ such that

$$
\left\langle x^{*}-x, J\left(V x^{*}-x^{*}\right)\right\rangle \geq 0, \quad \forall x \in F(S) .
$$

By Lemma 4.1, the hierarchical variational inequality problem in Banach space (4.1) is equivalent to the following fixed point equation:

$$
x^{*}=P_{F(S)} V\left(x^{*}\right) .
$$

Letting $C=F(S)$ and $Q=F\left(P_{F(S)} V\right)$ (the fixed point set of $\left.P_{F(S)} V\right)$ and $A=I$ (the identity mapping on $E$ ), then the hierarchical variational inequality problem (4.1) for a mapping $S$ with respect to a mapping $V$ in Banach space is equivalent to the following split common fixed point problem in Banach space:

to find $x \in C$ such that $x \in Q$.

Therefore the set of solutions of hierarchical variational inequality problem (4.1) is just the set of solutions of split common fixed point problem (4.3).

In Theorem 3.1, we take $E_{1}=E_{2}=E, A=I, T(t)=P_{F(S(t))} V(t), J_{1}=J_{2}=J$ (where $J$ is the normalized duality mapping on $E$ ), the following conclusion can be obtained from Theorem 3.1 immediately.

Theorem 4.3 Let E be a real uniformly convex and 2-uniformly smooth Banach space satisfying Opial's condition and with the best smoothness constant $k$ satisfying $0<k<\frac{1}{\sqrt{2}}$, Let $\{S(t): t \geq 0\}: E \rightarrow E$ be uniformly asymptotically regular family of asymptotically nonexpansive semigroup with a bounded measurable function $L^{(1)}(t):[0, \infty) \rightarrow[1, \infty)$ satisfying $\lim _{t \rightarrow \infty} L^{(1)}(t)=1$ and $C:=\bigcap_{t \geq 0} F(S(t)) \neq \emptyset$. Let $\{V(t): t \geq 0\}: E \rightarrow E$ be a semigroup and $\{T(t): t \geq 0\}:=\left\{P_{F(S(t))} V(t): t \geq 0\right\}$ be uniformly asymptotically regular family of asymptotically nonexpansive semigroup with a bounded measurable function $L^{(2)}(t):[0, \infty) \rightarrow[1, \infty)$ satisfying $\lim _{t \rightarrow \infty} L^{(2)}(t)=1$ and $Q:=\bigcap_{t \geq 0} F(T(t)) \neq \emptyset$. Let $\left\{x_{n}\right\}$ be a sequence generated by $x_{1} \in E$,

$$
\left\{\begin{array}{l}
z_{n}=x_{n}+\gamma\left(T\left(t_{n}\right)-I\right) x_{n}, \quad \forall n \geq 1 \\
x_{n+1}=\left(1-\alpha_{n}\right) z_{n}+\alpha_{n} S\left(t_{n}\right)\left(z_{n}\right)
\end{array}\right.
$$

where $\left\{t_{n}\right\}$ is a sequence of real numbers, $\left\{\alpha_{n}\right\}$ is a sequence in $(0,1)$ and $\gamma$ is a positive constant satisfying 
(1) $t_{n}>0$ and $\lim _{n \rightarrow \infty} t_{n}=\infty$;

(2) $L(t)=\max \left\{L^{(1)}(t), L^{(2)}(t)\right\}$ and $\sum_{n=1}^{\infty}\left(L^{2}\left(t_{n}\right)-1\right)<\infty$;

(3) $M=\sup _{n} L^{2}\left(t_{n}\right), \liminf _{n \rightarrow \infty} \alpha_{n}\left(1-\alpha_{n}\right)>0$, and $0<\gamma<\min \left\{\frac{1-2 k^{2}}{\|A\|^{2} M}, \frac{1}{\|A\|^{2}}\right\}$.

(I) If $\Gamma_{1} \neq \emptyset$ (the set of solutions of hierarchical variational inequality problem (4.1) is nonempty), then the sequence $\left\{x_{n}\right\}$ converges weakly to a split common fixed point $x^{*} \in \Gamma_{1}$.

(II) In addition, if $\Gamma_{1}=\{p \in C: A p \in Q\} \neq \emptyset$ and there exists at least one $S(t) \in\{S(t): t \geq 0\}$ that is semi-compact, then $\left\{x_{n}\right\}$ converges strongly to a split common fixed point $x^{*} \in \Gamma_{1}$.

\section{Competing interests}

The authors declare that they have no competing interests.

\section{Authors' contributions}

Both authors contributed equally to this work. Both authors read and approved the final manuscript.

\section{Author details}

${ }^{1}$ College of Statistics and Mathematics, Yunnan University of Finance and Economics, Kunming, Yunnan 650221, P.R China. ${ }^{2}$ School of Information Engineering, The College of Arts and Sciences Yunnan Normal University, Kunming, Yunnan 650222, P.R. China.

\section{Acknowledgements}

The authors would like to express their thanks to the reviewers and editors for their helpful suggestions and advices. This work was supported by the National Natural Science Foundation of China (Grant No. 11361070).

Received: 30 January 2016 Accepted: 22 September 2016 Published online: 30 September 2016

\section{References}

1. Goebel, K, Kirk, WA: A fixed point theorem for asymptotically nonexpansive mappings. Proc. Am. Math. Soc. 35 , $171-174(1972)$

2. Zhang, XF, Wang, L, Ma, ZL, Qin, LJ: The strong convergence theorems for split common fixed point problem of asymptotically nonexpansive mappings in Hilbert spaces. J. Inequal. Appl. 2015, Article ID 1 (2015)

3. Wangkeeree, R, Preechasilp, P: The general iterative methods for asymptotically nonexpansive semigroups in Banach spaces. Abstr. Appl. Anal. 2012, Article ID 695183 (2012). doi:10.1155/2012/695183

4. Sunthrayuth, P, Kumam, P: Fixed point solutions of variational inequalities for a semigroup of asymptotically nonexpansive mappings in Banach spaces. Fixed Point Theory Appl. 2012, Article ID 177 (2012)

5. Censor, Y, Elfving, T: A multiprojection algorithm using Bregman projection in a product space. Numer. Algorithms 8 , 221-239 (1994)

6. Byrne, C: Iterative oblique projection onto convex subsets and the split feasibility problems. Inverse Probl. 18 441-453 (2002)

7. Censor, Y, Bortfeld, T, Martin, B, Trofimov, T: A unified approach for inversion problem in intensity-modulated radiation therapy. Phys. Med. Biol. 51, 2353-2365 (2006)

8. Censor, Y, Elfving, T, Kopf, N, Bortfeld, T: The multiple-sets split feasibility problem and its applications. Inverse Probl. 21, 2071-2084 (2005)

9. Censor, Y, Motova, A, Segal, A: Pertured projections and subgradient projections for the multiple-sets split feasibility problems. J. Math. Anal. Appl. 327, 1244-1256 (2007)

10. Moudafi, A: The split common fixed point problem for demi-contractive mappings. Inverse Probl. 26, 055007 (2010)

11. Chang, SS, Wang, L, Tang, YK, Yang, L: The split common fixed point problem for total asymptotically strictly pseudocontractive mappings. J. Appl. Math. 2012, Article ID 385638 (2012). doi:10.1155/2012/385638

12. Chang, SS, Cho, YJ, Kim, JK, Zhang, WB, Yang, L: Multiple-set split feasibility problems for asymptotically strict pseudocontractions. Abstr. Appl. Anal. 2012, Article ID 491760 (2012). doi:10.1155/2012/491760

13. Quan, J, Chang, SS, Zhang, X: Multiple-set split feasibility problems for $k$-strictly pseudononspreading mapping in Hilbert spaces. Abstr. Appl. Anal. 2013, Article ID 342545 (2013). doi:10.1155/2013/342545

14. Moudafi, A: A note on the split common fixed point problem for quasi-nonexpansive operators. Nonlinear Anal. 74 4083-4087 (2011)

15. Cholamjiak, $\mathrm{P}$, Shehu, Y: Fixed point problem involving an asymptotically nonexpansive semigroup and a total asymptotically strict pseudocontraction. Fixed Point Theory Appl. 2014, Article ID 131 (2014)

16. Takahashi, W: Iterative methods for split feasibility problems and split common null point problems in Banach spaces. In: The 9th International Conference on Nonlinear Analysis and Convex Analysis, Chiang Rai, Thailand, January 21-25 (2015)

17. Tang, J, Chang, S-S, Wang, L, Wang, X: On the split common fixed point problem for strict pseudocontractive and asymptotically nonexpansive mappings in Banach spaces. J. Inequal. Appl. 2015, Article ID 305 (2015)

18. Xu, HK: Inequalities in Banach spaces with applications. Nonlinear Anal., Theory Methods Appl., 16, 1127-1138 (1991)

19. Chang, SS, Cho, YJ, Zhou, H: Demi-closed principle and weak convergence problems for asymptotically nonexpansive mappings. J. Korean Math. Soc. 38, 1245-1260 (2001)

20. Tan, KK, Xu, HK: Approximating fixed points of nonexpansive mappings by the Ishikawa iteration process. J. Math Anal. Appl. 178, 301-308 (1993)

21. Takahashi, W: Nonlinear Functional Analysis. Yokohama Publishers, Yokohama (2000) 